\title{
Crosstalk between peripheral and the brain-resident immune components in epilepsy
}

\author{
Xiaopeng $\mathrm{Mu}^{1,2}$, Xiuchun Zhang ${ }^{1}$, Honghua $\mathrm{Gao}^{2}$, Lianbo $\mathrm{Cao}^{2}$, Qingchang $\mathrm{Li}^{3}$, Chuansheng Zhao ${ }^{1,4, *}$ \\ ${ }^{1}$ Neurology, The First Hospital of China Medical University, 110001 Shenyang, Liaoning, China \\ ${ }^{2}$ Neurology, The Fourth Hospital of China Medical University, 110032 Shenyang, Liaoning, China \\ ${ }^{3}$ Department of Pathology, The First Hospital of China Medical University, 110001 Shenyang, Liaoning, China \\ ${ }^{4}$ Stroke Center, The First Hospital of China Medical University, 110001 Shenyang, Liaoning, China \\ *Correspondence: cszhao@cmu.edu.cn (Chuansheng Zhao)
}

\section{DOI:10.31083/j.jin2101009}

This is an open access article under the CC BY 4.0 license (https://creativecommons.org/licenses/by/4.0/).

Submitted: 14 March 2021 Revised: 30 March 2021 Accepted: 31 May 2021 Published: 28 January 2022

Epilepsy is one of the most common neurology diseases. It is characterized by recurrent, spontaneous seizures and accompanied by various comorbidities which can significantly affect a person's life. Accumulating evidence indicates an essential pathophysiological role for neuroinflammation in epilepsy, which involves activation of microglia and astrocytes, recruitment of peripheral leukocytes into the central nervous system, and release of some inflammatory mediators, including pro-inflammatory factors and anti-inflammatory cytokines. There is complex crosstalk between the central nervous system and peripheral immune responses associated with the progression of epilepsy. This review provides an update of current knowledge about the contribution of this crosstalk associated with epilepsy. Additionally, how gut microbiota is involved in epilepsy and its possible influence on crosstalk is also discussed. Such recent advances in understanding suggest innovative methods for targeting the molecules correlated with the crosstalk and may provide a better prognosis for patients diagnosed with epilepsy.

\section{Keywords}

Epilepsy; Neuroinflammation; Blood brain barrier; Microglia; CNS immunity; Peripheral immunity; Cut microbiota

\section{Introduction}

Epilepsy, one of the most common neurology diseases, affects nearly 65 million individuals worldwide [1]. It is a clinical entity characterized by recurrent, stereotypical, and spontaneous seizures (a process is known as "epileptogenesis", which leads to the onset and progression of the disease), followed by various comorbidities that seriously affect a person's life. Accumulating experimental and clinical data has shown innate and adaptive immunity to be activated and that related inflammatory responses may be induced in epileptogenic foci $[2,3]$. The inflammatory response, termed "neuroinflammation", is restricted to brain resident cells, including neurons, microglia, and astrocytes [2, 4]. Furthermore, it has been suggested that neuroinflammatory signals play a significant role in the progression of epilepsy [5], which involves different conditions, such as release of inflamma- tory factors (involving pro-inflammatory cytokines and antiinflammatory factors), activation of microglia and astrocytes, as well as recruitment of peripheral leukocytes into the central nervous system (CNS) [2, 6].

Seizures may induce blood-brain barrier (BBB) leakage [7], which may contribute to crosstalk between resident and peripheral immune responses; specifically, resultant BBB dysfunction may provide a favorable microenvironment for communication between peripheral immune cells (e.g., monocytes and macrophages) and CNS resident immune cells (e.g., microglia and astrocytes), which may be involved in neurogenesis, synaptogenesis, neurotransmission, and angiogenesis after epilepsy or seizures [8-12].

Importantly, the role of gut microbiota has become an increasing focus in neurological investigations. Lines of evidence have already shown that they are implicated in immunity, inflammation, and central and peripherally associated signaling pathways related to epileptogenesis [13]. Additionally, several lines of evidence have also demonstrated that the composition of gut microbiota can impact not only susceptibility to epilepsy but also its progression [14, 15].

First, evidence originating from studies investigating how the peripheral immune responses and CNS immune responses communicate with each other in epilepsy is reviewed from various perspectives. The goal is to identify novel targets for intervention. Second, the effects of gut microbiota on neuro-immune crosstalk are discussed.

\section{Monocytes/macrophages}

There is growing evidence that monocytes which invade from the peripheral circulation contribute significantly to neuroinflammation and the inevitable consequences that follow a brain insult [16]. For example, in an animal model of encephalitis-induced seizures and hippocampal damage, after the injection of Theiler's virus into the brain, two groups have separately shown that brain-infiltrated inflammatory monocytes injure the hippocampus $[17,18]$, which gives rise 
to the progression of acute seizures [19]. Intriguingly, inhibiting monocyte invasion by injection of clodronate liposomes did not prevent hippocampal damage in a viral encephalitis model [20]. Nevertheless, neuroinflammation accompanied by microglial activation and the infiltration of monocytes was detected in both animal models and patients with temporal lobe epilepsy (TLE) [21-23]. Taken together, these findings suggest that infiltrating monocytes may in these circumstances be a potential target for preventing or modifying epilepsy.

Macrophages originate from monocytes and enter the CNS via the peripheral circulation after CNS injury [24]. Macrophages can be divided into pro-inflammatory M1 and anti-inflammatory M2 phenotypes [25]. M1 macrophages are neurotoxic, while the M2 subtype enhances axonal regrowth after CNS insult [26-28]. Interestingly, following spinal cord injury (SCI), a population of macrophages derived from infiltrating monocytes facilitates recovery via the antiinflammatory cytokine interleukin (IL)-10 [29].

Importantly, chemokines are significant proinflammatory mediators which make leukocytes penetrate into the brain following seizures. C-C motif chemokine ligand (CCL)2, alternatively named monocyte chemoattractant protein-1 (MCP-1), serves as a chemoattractant for the monocyte lineage, which itself is constituted by microglia, monocytes, and macrophages [30-33]. The monocyte lineage could interpret the enhanced expression of monocytes or macrophage in patients with epilepsy and their animal models. An increased level of CCL2, produced by macrophages, monocytes or astrocytes, results in disruption of the BBB [34], thus contributing to epileptogenesis and the onset of epilepsy [3537]. With the exception of CCL2, tumor necrosis factor- $\alpha$ (TNF- $\alpha$ ) and IL- $\beta$ have been discovered to influence the recruitment and function of monocytes [38-40]. Furthermore, IL- 6 and TNF- $\alpha$ produced by infiltrating macrophages and resident microglia, have implications for the progression of acute seizures induced by Theiler's murine encephalomyelitis virus (TMEV) [19]. A recent study has demonstrated that preventing CCR2+ monocytes from penetrating the brain following status epilepticus (SE) contributed to neuroprotective outcomes, including lessened BBB opening, dampened inflammation, and enhanced functional recovery [41]. With respect to seizures and epilepsy, some experiments have shown that CCL2 is highly up-regulated in models of SE and patients with epilepsy [41-45]. Signal transducer and activator of transcription 3 (STAT3) activation in microglia/macrophages was triggered by CCL2-CCR2 signaling, then it facilitated to the generation of IL- $1 \beta$ which results in neuronal cell death after seizures [42]. Additionally, it has been revealed that there is an apparent decrease in monocyte infiltration into the brain following SE while CCR2 is suppressed, further demonstrating the importance of the CCL2CCR2 axis [41, 42]. It is worth noting that 2-cyano-3,12dioxolane-1,9-dien-28-oic acid methyl ester (CDDO-Me) reduces both SE-induced monocyte infiltration in the fron- toparietal cortex (FPC) and microglial activation, by suppressing CCL2 expression and p38 mitogen-activated protein kinase (p38 MAPK) signaling, independent of the activity of nuclear factor-erythroid 2-related factor 2 (Nrf2) [46].

CCR5 and its ligands have further been shown to be involved in vascular inflammation, while lowered expression of CCR 5 may be neuroprotective and lead to increased neurogenesis [47]. Endogenous astrocytic transforming growth factor (TGF)- $\beta$ signaling inhibits CCL5 generation via the nuclear factor- $\kappa \mathrm{B}(\mathrm{NF}-\kappa \mathrm{B})$ signaling pathway, reducing CCL5mediated recruitment of macrophages and T-cells to undamaged places within an infected brain [48].

\section{T-lymphocytes}

Lymphocytes infiltrate the CNS accompanied by monocytes, macrophages, and neutrophils following SE [21, 49, 50], which leads to BBB disruption and accelerates epileptogenesis $[49,51]$. Notably, CD ${ }^{+} \mathrm{T}$-cell infiltration into the CNS has been shown both for mice following SE induced by kainate and for TLE patients who undergo epilepsy surgery [22].

A recent experiment showed a biphasic increase of CD45 ${ }^{+}$ immune cells in the hippocampus was implicated in innate macrophages during the first four days as well as $\mathrm{CD}^{+}$ T-lymphocytes at 28 days following pilocarpine-induced SE. Correspondingly, one study has suggested pilocarpineinduced SE of C57BL/ 6 mice leads to either the infiltration of activated macrophages into the hippocampus or activation of resident glial cells, which are predicted to induce a proinflammatory immune response that may attract more immune cells and allow T-lymphocytes to enter the CNS by affecting the permeability of the BBB [52]. Infiltrated T-cell then an attack on distinct hippocampal neurons sufficient to make a contribution to cellular and structural dynamics that displayed signs of limbic encephalitis that induced TLEhippocampal sclerosis (HS) [53].

Furthermore, the epileptic brain was observed to be infiltrated by $\mathrm{CD}^{+}$cytotoxic and activated memory $\mathrm{CD} 4^{+}$ helper T lymphocytes. In the study, IL-17-producing $\gamma \delta \mathrm{T}$ lymphocytes, which are positively related to seizure severity, were found in the epileptogenic zone for the first time; alternatively, the number of regulatory T-cells (Tregs) infiltrating the brain was negatively correlated with the severity of seizure [54].

Future studies should be conducted to explore specific signaling pathways of peripheral immune cells, especially in the context of refractory epilepsy, to provide further intervention targets originating in the peripheral circulation.

\section{Astrocyte \\ 4.1 Astrocyte, BBB disruption and epilepsy}

Astrocytes take part in regulating the immune response in the CNS, maintaining the BBB, secreting cytokines (i.e., chemokines and neurotrophic factors $[55,56])$ as well as generating anti-epileptogenic neurosteroids [57]. Astrocytes 
also take part in the modulation of inhibitory and excitatory synapses as well as the mediation of synaptogenesis [58], which significantly contributes to neurogenesis related to the mediation of the microenvironment $[59,60]$. Some reactive astrocytes have been proposed to re-express factors essential for synaptogenesis [61] and axonal guidance [62] and possibly contribute to cerebral plasticity and repair. Reactive astrocytes can be divided into an A1 phenotype (serving a neurotoxic role) and an A2 phenotype (serving a neuroprotective role) [63]. Disruption of the BBB has been extensively demonstrated both in patients and animals following acute seizures [35, 49, 64-66]. Astrocytes in the epileptic brain also undergo morphological and functional changes, including altered expression of $\mathrm{K}^{+}$and water channels, which affect BBB function [67-69]. Cytokines produced by perivascular microglia and astrocytes promote the breakdown of the BBB in epilepsy [70]. For example, vascular endothelial growth factor (VEGF), astrocytic IL- $1 \beta$ and microglial IL- $1 \beta$ have been revealed to increase BBB permeability [71]. There are also other mechanisms for BBB disruption after seizures. For instance, increases in glutamate levels in the brain induced by seizures may lead to barrier dysfunction $[72,73]$. A recent experiment has revealed that the release of glutamate induced by seizures enhances the levels of matrix metalloproteinases (MMP-9 and MMP-2) in the BBB, which leads to barrier dysfunction [74]. Another MMP member such as MMP-12, is also involved in BBB disruption after seizures and inhibition of it could protect hippocampal neurons against cell death occurring after SE [75]. However, a recent study has shown that immune-associated cells and MMP-2 and MMP-9 are essential for promoting the migration of leukocytes [76]. Furthermore, leukocyte-originated inflammatory factors, such as interferon- $\gamma$ (IFN- $\gamma)$, TNF- $\alpha$, and the homeostasis between them, are activated by astrocytes and mediate the secretion of MMP-9, which has an impact on the chemokines which infiltrate the T-cells into the CNS [76]. Additionally, inflammatory pathways activated by activated astrocytes may facilitate the development of seizures $[77,78]$.

\subsection{Crosstalk between astrocytes and peripheral infiltrated cells}

Astrocytes are able to communicate with infiltrated peripheral immune components [55]. While the integrity of the BBB is compromised, peripheral adaptive and innate immune cells, involving neutrophils, monocytes, T-cells, and Bcells, may infiltrate into the CNS, where they mediate different effects including those that are neuroprotective or neurotoxic [16, 22]. Moreover, peripheral leukocytes seem to contribute to the progression of epilepsy by interfering with the BBB [79]. Interestingly, the recruitment of leukocytes is thought to be caused by chemoattractant factors activated by microglia, as well as in response to cytokine signaling [38]. The peripheral leukocytes stick to the endothelial cells of a capillary via adhesion molecules and their relevant ligands and extravasate through the $\mathrm{BBB}$, and produce local inflammation within the BBB. The inflammation contributes to changes in neurotransmission, probably by disrupting the
$\mathrm{BBB}$, ultimately leading to the changes in susceptibility to seizure and possible epilepsy [49]. Indeed, several studies have revealed that there is successive recruitment of peripheral immune cells into the CNS after a seizure, paralleled by activation of immune cells in both the periphery and CNS [80, 81]. The mechanism of leukocyte-endothelial interactions and leukocyte trafficking has been confirmed to make an important contribution to the pathogenesis of seizures and epilepsy [82, 83]. A leaky barrier can cause seizures via a positive feedback, thereby promoting the progression of epilepsy. Thus, barrier leakage is not only a result but also a cause of seizures and epilepsy [84].

Astrogliosis is considered to be a protective reaction of astrocytes to inflammation, trauma, pathological neurodegeneration, or ischemic insult [85]. Pro-inflammatory cytokines may greatly influence astrocytes and preserve astrogliosis as well as enhance epileptogenesis [86, 87], which can be generated by activated microglia [88] and reactive astrocytes $[89,90]$. Cytokines are involved in both reactive astrogliosis [91] and epilepsy [5]. Chemokine C-X-C ligand (CXCL)1/CXCR2 signaling has been reported to mediate reactive astrogliosis which is closely related to epileptogenesis [92]. Additionally, inhibiting scar formation in STAT3knockout mice may induce extended lesions, upregulate the loss of neurons and enhance functional deficits after CNS injury, whereas, promoting the formation of scar in mice by a protein suppressor of cytokine signaling 3-knockout exerts the opposite effect $[93,94]$. This suggests that astrogliosis and glial scar formation have dual roles and may be neuroprotective in a given context after brain injury [95].

IL- $1 \beta$, IL- 6 , and TNF- $\alpha$ as the cytokines associated with astrogliosis and epilepsy, are widely studied, have been shown to regulate astrocytic responses, and downregulate the astrocyte purinergic receptor P2Y1 (P2Y1R) to facilitate tissue repair [63]. Additionally, high expression of IL-6 can result in lowered astrocytic glutamate uptake via an excitatory amino acid transporter 2 (EAAT2), and the enhancement of the glutamate release via ameliorating astrocytic cysteine or glutamate antiporter's activity [96]. Ultimately, IL-6 increases the permeability of the BBB [97]. Some studies have found that preventing astrocytic TGF $\beta$ R1 activation blocks the progress of epilepsy in a pilocarpine model of epileptogenesis [98].

In the mouse model of TLE induced bylithiumpilocarpine, specific genetic elimination of brain-derived neurotrophic factor (BDNF) in astrocytes prevented an increase in the number of firing neurons; $\operatorname{TrkB}$ in astrocytes was genetically deleted and greatly preserving the spatial learning abilities, which suggested that the astrocytic BDNF and $\operatorname{TrkB}$ molecules serve as promising targets for the treatment of TLE [99]. The restoration of the normal mode of astroglial $\mathrm{Ca}^{2+}$-dependent activity by blocking P2Y1Rmediated signals suggests that changed synaptic plasticity may be primarily related to aberrant crosstalk between astrocytes in the epileptic hippocampus [100]. Recently, a 
study showed that Fingolimod played an anti-seizure role in experimental TLE via impairing T-cell migration to the CNS, indicating that infiltrated $\mathrm{T}$-cells and their releasing cytokines may be involved in epileptogenesis [101].

\section{Microglia \\ 5.1 Microglia and epilepsy}

Microglia may have both pro-epileptic and anti-epileptic effects on the epileptic brain [102]. On the one hand, the activation of microglia may exert an anti-epileptic role by suppressing activity in abnormal neural circuits after SE [103, 104]. On the other hand, chronic activation of microglia may play a pro-epileptic role via inflammatory immune responses [105]. A growing body of evidence has shown that microglial activation can also be beneficial, as it is capable of increasing neurotrophic and anti-inflammatory factors, producing antiepileptogenic neurosteroids [106], clearing debris, and possibly accelerating repair $[107,108]$. Therefore, short-term microglial activation might be favorable [109], whereas, the chronic activation of microglia is possibly detrimental [110] to the development of epilepsy. Reactive microglia have been discovered in animal models of TLE [111] and in surgical samples of patients with epilepsy [112, 113].

Recently, a variety of studies have indicated that activation of microglia induced by seizures in early life could aggravate susceptibility to seizures in later life [114-116]. Also, the activation of microglia in response to seizures is considered to be the crucial mediator of post-seizure cytokine production [117-119]. Microglia are the primary producers of pro-inflammatory cytokines in response to brain injury [120]. Activated microglial cells can generate cytokines such as IL- $1 \beta$ and TNF- $\alpha$ at the onset of seizure [121-123]. High mobility group protein B1 (HMGB1), has been shown to be involved in the toll-like receptor 4 (TLR 4$) / N F-~ \kappa B$ signaling pathway, resulting in activation of microglia in seizures [124].

Adult seizures may induce a variety of pathological outcomes, including neuronal loss, mossy fiber sprouting, and gliosis and synaptic reorganization in the hippocampus [125127]. Microglia can regulate structural and functional alteration of the hippocampus following early-life seizures [128], and microglia can also take part in neurogenesis [129, 130], mediation of axonal processes [131], synapse formation [132, 133], neurotransmitter clearance [134], as well as neuronal phagocytosis [135]. Recent evidence suggests that different phenotypes of microglia may have either positive or negative effects on neurogenesis after brain damage. For example, the M1 phenotype of activated microglia undermines basal neurogenesis [136, 137] and axonal regeneration [138, 139]. On the contrary, the M2 phenotype of activated microglia enhances basal neurogenesis $[137,140]$ and oligodendrogenesis [137]. The activation state of microglia has been viewed as a key factor in BBB repair and angiogenesis [141] as well as synaptic plasticity after CNS injuries [142, 143]. Therefore, the correct phenotype must be enhanced at the right time to promote appropriate neural repair after CNS damage [144].

\subsection{Crosstalk between microglia and peripheral infiltrated cells}

A recent experiment revealed that betaine induced microglia to transform into the M2 phenotype perhaps via hindering TLR4/NF- $\kappa \mathrm{B}$ signaling [145]. Concordantly, another experiment showed that dynorphin activating kappa opioid receptor (KOR) stimulated microglia polarization toward the M2 phenotype through the TLR4/NF- $\kappa \mathrm{B}$ pathway. This may provide a novel method for the treatment of neuroinflammatory diseases including epilepsy [146]. One study has suggested that Protein kinase R (PKR)-like endoplasmic reticulum (ER) kinase (PERK) siRNA not only downregulated IFN- $\beta$ expression, transcription factor interferon regulatory factor 3 (IRF-3) phosphorylation, TANKbinding kinase 1 (TBK-1) phosphorylation, and Stimulator of Interferon Genes (STING) phosphorylation, but also greatly decreased M1 microglia polarization with a transfer to M2 polarization, as well as lowering CXCL10- production and T-helper 1 (Th1) lymphocytes trafficking into the brain and white matter injury [147]. Rosiglitazone reversed microglial polarization to the M2 phenotype and played a neuroprotective role in SE induced by pilocarpine without remarkably changing inflammation in the brain [148]. Additionally, inhibiting the HMGB1-RAGE (receptor for advanced glycation end products) axis effectively hinders macrophages/microglia's pro-inflammatory polarization, with a neuroprotective outcome of reducing the loss of neurons and myelin, and ameliorating functional recovery after SCI in rats [149].

Transient receptor potential vanilloid type 1 (TRPV1) is a nonselective cationic channel that is temperature-sensitive and usually activated by hyperthermia $[150,151]$. It is generally suggested that activation of TRPV1 directly facilitates synaptic transmission and neurogenesis [152, 153]. More interestingly, a recent study has demonstrated that TRPV1 makes a contribution to the progression of repetitive hyperthermia-induced seizures (rFS) by blocking the activation of microglial M2 phenotype via TGF- $\beta 1$ signaling, which serves as an additional method for the activation of the microglial M1 phenotype to promote seizure [154].

Recently, it has been found that myeloid differentiation factor 88 (MyD88) is upregulated in epilepsy models, and that suppression of MyD88 inhibits seizure and neuronal apoptosis $[155,156]$. Importantly, inhibition or deficiency of MyD88 has been found to transform microglia and macrophages from the M1 to the M2 phenotype, to finally ameliorate the neurological outcome after SE [157]. Collectively, microglia and their phenotype transformation make an important contribution to the neuro-immune crosstalk between the CNS and the peripheral immune response, an interaction which is likely involved in epileptogenesis.

\section{Gut microbiota and epilepsy}

The role of gut microbiota has become increasingly attractive in recent neurological research. The immune cells 
within intestinal tissues account for about $70 \%$ of the total number of human immune cells [158]. Many reports have shown that interplay exists between gut microbiota and CNS [159], which may influence neuroimmunity. It is known that microbiota and their metabolites are able to affect both human physiology and pathology [160]. For example, the short chain fatty acids (SCFAs), a gut microbiota metabolite, have been demonstrated to insert into the BBB via the bloodstream and directly influence its integrity [161]. The absence of gut microbes induces structural changes in the BBB, these are characterized by reduced tight junction protein levels, consequently enhancing the permeability of the BBB when compared with unaffected mice [162].

SCFAs serve as the necessary metabolites with antiinflammatory features and decreasing their level may enhance $\mathrm{BBB}$ permeability, which consequently enhances neuroinflammation [163]. Intriguingly, administrating sodium butyrate intravenously or intraperitoneally can inhibit BBB breakdown and encourage neurogenesis after traumatic brain injuries [164-166]. Additionally, treatment with a low dose of penicillin can increase the integrity of the BBB and increase the tight junction density in young mice through long-term alterations in gut microbiota [167].

Recent experiments have demonstrated that gut microbiota is involved in immunity, inflammation, and both central and peripherally associated signaling pathways related to epileptogenesis [13]. Indeed, the composition of the gut microbiota could impact not only human susceptibility to epilepsy but also its progression [14,15]. Gut microbiota is regarded as an early biomarker of epilepsy [168] and there is a strong correlation between the two [169]. Especially with relation to epilepsy, the gut microbiota can change the function of microglia and astrocytes, the metabolism of carbohydrates and amino acids, the activity of vagal neuronal activity, and hippocampal neurotransmitter release. The ketogenic diet $(\mathrm{KD})$ also plays an anti-epileptic role via microbiota [170]. A KD changes the gut microbiota [171, 172], facilitating selection of microbial interplays that reduce bacterial $\gamma$-glutamylation activity, lessen the level of peripheral ketogenic $\gamma$-glutamylated amino acids, upregulates bulk hippocampal GABA and glutamate ratios, as well as protects against seizures [172, 173]. Several other metabolic elements have also been thought to be involved in the anticonvulsant role of a $\mathrm{KD}$, such as changes in the plasma levels of ketone bodies, polyunsaturated fatty acids, brain $\mathrm{pH}$, and altered regulation of the synthesis of neuropeptides and peripheral hormones in response to a KD [174].

Recent studies have reported that both physical and psychological stress factors have an impact on gut microbiota [175] and it has further been suggested that stress-related changes in gut microbiota may influence the progression of seizures [168]. Recently, it has also been demonstrated that dysbiosis related to chronic stress can promote epileptogenesis, while fecal microbiota transplantation (FMT) from sham-stressed controls transplanted to rats with chronic stress eases the pro-epileptic role of restraint stress [168].

Some experiments have shown that gut microbiota may be involved in both central and peripheral immune growth processes, as well as in the maintenance of the host homeostasis $[176,177]$. It has been demonstrated that both a large number of cases of epilepsy preserve an immune-related basis and that immunotherapy is effective in retarding the development of epilepsy [178]. Observational studies have also confirmed that patients with epilepsy may obtain benefits from immunotherapy for controlling seizures [179-182].

The level of IL-17A has been reported to be greatly upregulated in the peripheral blood or cerebrospinal fluid (CSF) in those with epilepsy and to be associated with seizure frequency and severity [183]. The secretion of IL-17 and IL-6 can be mediated by Bacteroides, and Prevotella may generate great amounts of SCFAs to take part in regulating cerebral functions [172]. Importantly, symbiotic gut bacteria have been proposed to modulate Th17 cells [184]. In pediatric epilepsy and Rasmussen encephalopathy, $\gamma \delta$ T cells have been considered as a component of infiltrating lymphocytes into the brain $[185,186]$, which are located in the gut epithelium and contribute to intestinal homeostasis, inflammation, and repair. Except for Tregs, SCFAs have also been demonstrated to induce retinoic acid to express in the intestine. This can impede the differentiation of Th17 and enhance the proliferation of Treg, thereby being beneficial to neuroinflammation [187].

There is evidence showing that inadequate neurogenesis can be alleviated by specific strains of probiotic bacteria, hence linking microbiota to hippocampal neuronal regrowth $[188,189]$.

Also, it is worth noting that recently the function of astrocytes has been found to be influenced by gut microbiota and the cross-talk between them may have great significance in the understanding of CNS diseases [190, 191]. Different kinds of gut bacteria may mediate the astrocytic inflammatory signaling response positively or negatively [191-193].

Increasingly, methods utilized for changing gut microbiota and reversing dysbiosis are emerging, involved in KD, treatment by probiotics, and as FMT [168, 194-197].

\section{Concluding remarks}

This review has focused on the crosstalk between CNS immunity and peripheral immunity in epilepsy (Fig.1), an interaction that possibly provides intervention targets for epilepsy, in particular the specific immune-associated signaling molecules involved in the crosstalk to treat drug-resistant epilepsy. In pathological conditions (i.e., here, epilepsy), peripheral monocytes (or macrophages), T-cells and metabolites of gut microbiota can enter the brain through an impaired BBB and thus interact with central immune components (e.g., microglia, astrocyte). Some possible related pathways may be involved in the crosstalk process, such as the Wingless/integrase-1 (Wnt) signaling pathway, the mammalian target of rapamycin (mTOR) signaling pathway, and 


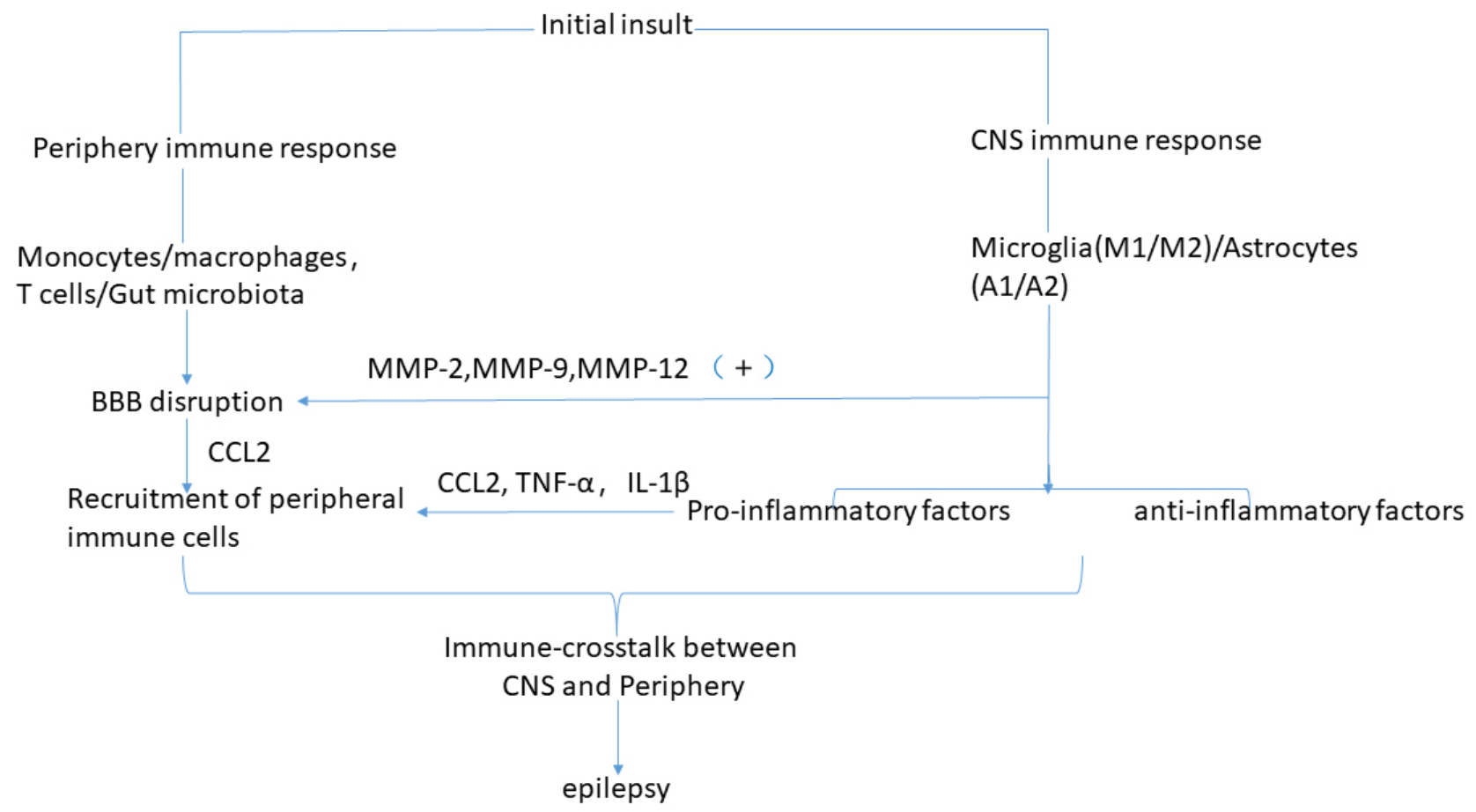

Fig. 1. Pathophysiological cascade of events leading from inflammation and microbiota to epilepsy. See Crosstalk between central immunity and peripheral immunity in epilepsy for explanation.

zinc signaling [198]. However, the mechanism that describes how and when the peripheral immune components infiltrate and influence the disease (especially during different disease periods) has not been fully elucidated and more study is required.

On the basis of recent articles, this review discovered differences in epilepsy and other diseases (such as stroke/amyotrophic lateral sclerosis (ALS)) in the crosstalk between peripheral and brain-resident immune components. For instance, an immune-related crosstalk between the CNS and the periphery has been clarified as beneficial for neuronal repair and functional recovery after a stroke [199]. In the context of ALS, peripheral immune components (e.g., monocytes/macrophages, T-cells) and gut microbiota metabolites can infiltrate into the spinal cord and directly interact with motor neurons (MNs) or surrounding microglia/astrocytes, potentially contributing to either protecting or injuring the MNs as well as resultantly correlating with the survival of patients with ALS [200]. However, crosstalk between the CNS and the periphery in epilepsy mentioned above ultimately contributes to the progression of disease.

Understanding how the crosstalk between the peripheral and the brain-resident immune system influences the initiation and progression of epilepsy may provide a potential approach for clinical treatment. Therefore, it is very important to understand how the peripheral immune components infiltrate into the CNS from the peripheral circulation and intervention at any part of the process may provide interesting and new outlooks into the treatment of epilepsy. Mesenchy- mal stem cells treatment [201] and immunomodulatory treatment for epilepsy has attracted increasing attention in recent years and needs to be further applied in the clinic. Gut microbiota, especially, play a major role in epilepsy and their alteration or regulation by exogenous intervention may reduce or prevent the disease. A growing number of treatments, containing KD [202], probiotics [203] and FMT [204] have been steadily employed, offering promise for the treatment of epilepsy and its complicated comorbidities. Further studies on gut microbiota and their metabolites in patients with refractory epilepsy will assist in the development of novel intervention targets in the occurrence and progression of the disease.

\section{Abbreviations}

CNS, central nervous system; BBB, blood brain barrier; TLE, temporal lobe epilepsy; IL, interleukin; SCI, spinal cord injury; CCL, C-C motif chemokine ligand; MCP-1, monocyte chemoattractant protein-1; TNF- $\alpha$, tumor necrosis factor$\alpha$; TMEV, Theiler's murine encephalomyelitis virus; SE, status epilepticus; STAT3, signal transducer and activator of transcription 3; CDDO-Me, 2-cyano-3,12-dioxolane-1,9dien-28-oic acid methyl ester; FPC, frontoparietal cortex; p38 MAPK, p38 mitogen-activated protein kinase; Nrf2, nuclear factor-erythroid 2-related factor 2; TGF, transforming growth factor; NF- $\kappa \mathrm{B}$, nuclear factor- $\kappa \mathrm{B}$; HS, hippocampal sclerosis; Tregs, regulatory $\mathrm{T}$ cells; VEGF, vascular endothelial growth factor; MMPs, matrix metalloproteinases; IFN$\gamma$, interferon- $\gamma$; CXCL, Chemokine C-X-C ligand; P2Y1R, 
purinergic receptor P2Y1; EAAT2, excitatory amino acid transporter 2; BDNF, brain-derived neurotrophic factor; HMGB1, high mobility group protein B1; TLR4, toll-like receptor 4; KOR, kappa opioid receptor; PKR, Protein kinase R; ER, endoplasmic reticulum; PERK, Protein kinase $\mathrm{R}$ (PKR)-like endoplasmic reticulum (ER) kinase; IRF-3, interferon regulatory factor 3; TBK-1, TANK-binding kinase 1; STING, Stimulator of Interferon Genes; Th1, Thelper 1; TRPV1, transient receptor potential vanilloid type 1; rFS, repetitive hyperthermia-induced seizures; MyD88, myeloid differentiation factor 88; SCFAs, short chain fatty acids; KD, ketogenic diet; FMT, fecal microbiota transplantation; CSF, cerebrospinal fluid; Wnt, Wingless/integrase-1; mTOR, mammalian target of rapamycin; ALS, amyotrophic lateral sclerosis; MNs, motor neurons.

\section{Author contributions}

$\mathrm{XM}$ drafted the paper; $\mathrm{XZ}$ have provided assistance in editing and writing the paper; HG, LG, QL and CZ have revised it strictly for important intellectual content. All authors contributed to editorial changes in the manuscript. All authors read and approved the final manuscript.

\section{Ethics approval and consent to participate Not applicable.}

\section{Acknowledgment}

We thank the anonymous reviewers for excellent criticism of the article.

\section{Funding}

This work is supported by the following grants: the Support Plan for Innovation Team of Liaoning Colleges and Universities (No.LT2019015); the Guidance Plan of Liaoning Key Research and Development Plan (No. 2019JH8/10300002); the Support Plan for Cultivate disciplines of China Medical University 2019; the Rejuvenate Liaoning Talents Project; China Medical University Highlevel Innovation Team Training Plan (No. 2017CXTD02).

\section{Conflict of interest}

The authors declare no conflict of interest.

\section{References}

[1] Devinsky O, Vezzani A, O'Brien TJ, Jette N, Scheffer IE, de Curtis M, et al. Epilepsy. Nature Reviews Disease Primers. 2018; 4: 18025.

[2] Vezzani A, French J, Bartfai T, Baram TZ. The role of inflammation in epilepsy. Nature Reviews Neurology. 2011; 7: 31-40.

[3] Aronica E, Crino PB. Inflammation in epilepsy: clinical observations. Epilepsia. 2011; 52: 26-32.

[4] Aronica E, Ravizza T, Zurolo E, Vezzani A. Astrocyte immune responses in epilepsy. Glia. 2012; 60: 1258-1268.

[5] Vezzani A, Balosso S, Ravizza T. Neuroinflammatory pathways as treatment targets and biomarkers in epilepsy. Nature Reviews Neurology. 2019; 15: 459-472.

[6] Ravizza T, Balosso S, Vezzani A. Inflammation and prevention of epileptogenesis. Neuroscience Letters. 2011; 497: 223-230.
[7] Löscher W. Epilepsy and Alterations of the Blood-Brain Barrier: Cause or Consequence of Epileptic Seizures or both? Handbook of Experimental Pharmacology. 2020. (in press)

[8] Araki T, Ikegaya Y, Koyama R. The effects of microglia- and astrocyte-derived factors on neurogenesis in health and disease. European Journal of Neuroscience. 2020. (in press)

[9] Andoh M, Ikegaya Y, Koyama R. Synaptic Pruning by Microglia in Epilepsy. Journal of Clinical Medicine. 2019; 8: 2170.

[10] Patel DC, Tewari BP, Chaunsali L, Sontheimer H. Neuron-glia interactions in the pathophysiology of epilepsy. Nature Reviews Neuroscience. 2019; 20: 282-297.

[11] Zhang Y, Zhu W, Yu H, Yu J, Zhang M, Pan X, et al. P2Y4/TSP$1 / \mathrm{TGF}-\beta 1 / \mathrm{pSmad} 2 / 3$ pathway contributes to acute generalized seizures induced by kainic acid. Brain Research Bulletin. 2019; 149: 106-119.

[12] Matsuda T, Nakashima K. Natural and forced neurogenesis in the adult brain: Mechanisms and their possible application to treat neurological disorders. Neuroscience Research. 2020; 166: 1-11.

[13] Lum GR, Olson CA, Hsiao EY. Emerging roles for the intestinal microbiome in epilepsy. Neurobiology of Disease. 2020; 135: 104576.

[14] Chen C, Lin C, Kao C. Irritable Bowel Syndrome Increases the Risk of Epilepsy: a Population-Based Study. Medicine. 2015; 94: e1497.

[15] De Filippo C, Cavalieri D, Di Paola M, Ramazzotti M, Poullet JB, Massart S, et al. Impact of diet in shaping gut microbiota revealed by a comparative study in children from Europe and rural Africa. Proceedings of the National Academy of Sciences of the United States of America. 2010; 107: 14691-14696.

[16] Prinz M, Priller J. The role of peripheral immune cells in the CNS in steady state and disease. Nature Neuroscience. 2017; 20: 136144.

[17] Howe CL, Lafrance-Corey RG, Sundsbak RS, Sauer BM, Lafrance $\mathrm{SJ}$, Buenz EJ, et al. Hippocampal protection in mice with an attenuated inflammatory monocyte response to acute CNS picornavirus infection. Scientific Reports. 2012; 2: 545.

[18] Howe CL, Lafrance-Corey RG, Sundsbak RS, Lafrance SJ. Inflammatory monocytes damage the hippocampus during acute picornavirus infection of the brain. Journal of Neuroinflammation. 2012; 9: 50.

[19] Cusick MF, Libbey JE, Patel DC, Doty DJ, Fujinami RS. Infiltrating macrophages are key to the development of seizures following virus infection. Journal of Virology. 2013; 87: 1849-1860.

[20] Waltl I, Käufer C, Bröer S, Chhatbar C, Ghita L, Gerhauser I, et al. Macrophage depletion by liposome-encapsulated clodronate suppresses seizures but not hippocampal damage after acute viral encephalitis. Neurobiology of Disease. 2018; 110: 192-205.

[21] Ravizza T, Gagliardi B, Noé F, Boer K, Aronica E, Vezzani A. Innate and adaptive immunity during epileptogenesis and spontaneous seizures: evidence from experimental models and human temporal lobe epilepsy. Neurobiology of Disease. 2008; 29: 142160.

[22] Zattoni M, Mura ML, Deprez F, Schwendener RA, Engelhardt $\mathrm{B}$, Frei K, et al. Brain infiltration of leukocytes contributes to the pathophysiology of temporal lobe epilepsy. The Journal of Neuroscience. 2011; 31: 4037-4050.

[23] Lu J, Steve TA, Wheatley M, Gross DW. Immune Cell Infiltrates in Hippocampal Sclerosis: Correlation with Neuronal Loss. Journal of Neuropathology and Experimental Neurology. 2017; 76: 206-215.

[24] Popovich PG, Hickey WF. Bone marrow chimeric rats reveal the unique distribution of resident and recruited macrophages in the contused rat spinal cord. Journal of Neuropathology and Experimental Neurology. 2001; 60: 676-685.

[25] Yunna C, Mengru H, Lei W, Weidong C. Macrophage M1/M2 polarization. European Journal of Pharmacology. 2020; 877: 173090.

[26] Mikita J, Dubourdieu-Cassagno N, Deloire MS, Vekris A, Biran M, Raffard G, et al. Altered M1/M2 activation patterns of mono- 
cytes in severe relapsing experimental rat model of multiple sclerosis. Amelioration of clinical status by M2 activated monocyte administration. Multiple Sclerosis. 2011; 17: 2-15.

[27] Kano F, Matsubara K, Ueda M, Hibi H, Yamamoto A. Secreted Ectodomain of Sialic Acid-Binding Ig-Like Lectin-9 and Monocyte Chemoattractant Protein-1 Synergistically Regenerate Transected Rat Peripheral Nerves by Altering Macrophage Polarity. Stem Cells. 2017; 35: 641-653.

[28] Zhang J, Sun J, Zheng Q, Hu X, Wang Z, Liang Z, et al. Low-level laser therapy 810-nm up-regulates macrophage secretion of neurotrophic factors via PKA-CREB and promotes neuronal axon regeneration in vitro. Journal of Cellular and Molecular Medicine. 2020; 24: 476-487.

[29] Shechter R, London A, Varol C, Raposo C, Cusimano M, Yovel G, et al. Infiltrating blood-derived macrophages are vital cells playing an anti-inflammatory role in recovery from spinal cord injury in mice. PLoS Medicine, 2009; 6: e1000113.

[30] Mahad D, Callahan MK, Williams KA, Ubogu EE, Kivisäkk P, Tucky B, et al. Modulating CCR2 and CCL2 at the blood-brain barrier: relevance for multiple sclerosis pathogenesis. Brain. 2006; 129: 212-223.

[31] Deng YY, Lu J, Ling EA, Kaur C. Monocyte chemoattractant protein-1 (MCP-1) produced via NF-kappaB signaling pathway mediates migration of amoeboid microglia in the periventricular white matter in hypoxic neonatal rats. Glia. 2009; 57: 604-621.

[32] Bozzi Y, Caleo M. Epilepsy, Seizures, and Inflammation: Role of the C-C Motif Ligand 2 Chemokine. DNA and Cell Biology. 2016; 35: 257-260.

[33] Gschwandtner M, Derler R, Midwood KS. More Than Just Attractive: How CCL2 Influences Myeloid Cell Behavior Beyond Chemotaxis. Frontiers in Immunology. 2019; 10: 2759.

[34] Yadav A, Saini V, Arora S. MCP-1: chemoattractant with a role beyond immunity: a review. Clinica Chimica Acta; International Journal of Clinical Chemistry. 2010; 411: 1570-1579.

[35] Marchi N, Angelov L, Masaryk T, Fazio V, Granata T, Hernandez $\mathrm{N}$, et al. Seizure-promoting effect of blood-brain barrier disruption. Epilepsia. 2007; 48: 732-742.

[36] Seiffert E, Dreier JP, Ivens S, Bechmann I, Tomkins O, Heinemann $\mathrm{U}$, et al. Lasting blood-brain barrier disruption induces epileptic focus in the rat somatosensory cortex. The Journal of Neuroscience. 2004; 24: 7829-7836.

[37] Broekaart DWM, Anink JJ, Baayen JC, Idema S, de Vries HE, Aronica E, et al. Activation of the innate immune system is evident throughout epileptogenesis and is associated with bloodbrain barrier dysfunction and seizure progression. Epilepsia. 2018; 59: 1931-1944.

[38] D’Mello C, Le T, Swain MG. Cerebral microglia recruit monocytes into the brain in response to tumor necrosis factoralpha signaling during peripheral organ inflammation. Journal of Neuroscience. 2009; 29: 2089-2102.

[39] Seleme MC, Kosmac K, Jonjic S, Britt WJ. Tumor Necrosis Factor Alpha-Induced Recruitment of Inflammatory Mononuclear Cells Leads to Inflammation and Altered Brain Development in Murine Cytomegalovirus-Infected Newborn Mice. Journal of Virology. 2017; 91: e01983-16.

[40] Paré A, Mailhot B, Lévesque SA, Juzwik C, Ignatius Arokia Doss PM, Lécuyer M, et al. IL- $1 \beta$ enables CNS access to CCR2hi monocytes and the generation of pathogenic cells through GM-CSF released by CNS endothelial cells. Proceedings of the National Academy of Sciences of the United States of America. 2018; 115: E1194-E1203.

[41] Varvel NH, Neher JJ, Bosch A, Wang W, Ransohoff RM, Miller $\mathrm{RJ}$, et al. Infiltrating monocytes promote brain inflammation and exacerbate neuronal damage after status epilepticus. Proceedings of the National Academy of Sciences of the United States of America. 2016; 113: E5665-E5674.

[42] Tian D, Peng J, Murugan M, Feng L, Liu J, Eyo UB, et al. Chemokine CCL2-CCR2 Signaling Induces Neuronal Cell Death via STAT3 Activation and IL-1 $\beta$ Production after Status Epilep- ticus. The Journal of Neuroscience. 2017; 37: 7878-7892.

[43] Cerri C, Genovesi S, Allegra M, Pistillo F, Püntener U, Guglielmotti A, et al. The Chemokine CCL2 Mediates the Seizureenhancing Effects of Systemic Inflammation. The Journal of Neuroscience. 2016; 36: 3777-3788.

[44] Choi J, Nordli D, Alden T, DiPatri A, Laux L, Kelley K, et al. Cellular injury and neuroinflammation in children with chronic intractable epilepsy. Journal of neuroinflammation, 2009; 19:6-38.

[45] Arisi GM, Foresti ML, Katki K, Shapiro LA. Increased CCL2, CCL3, CCL5, and IL-1 $\beta$ cytokine concentration in piriform cortex, hippocampus, and neocortex after pilocarpine-induced seizures. Journal of Neuroinflammation. 2015; 12: 129.

[46] Kim JE, Park H, Lee JE, Kang TC. CDDO-Me Inhibits Microglial Activation and Monocyte Infiltration by Abrogating NFxB- and p38 MAPK-Mediated Signaling Pathways Following Status Epilepticus. Cells. 2020; 9: 1123.

[47] Louboutin J, Chekmasova A, Marusich E, Agrawal L, Strayer DS. Role of CCR5 and its ligands in the control of vascular inflammation and leukocyte recruitment required for acute excitotoxic seizure induction and neural damage. The FASEB Journal. 2011; 25: 737-753.

[48] Cekanaviciute E, Dietrich HK, Axtell RC, Williams AM, Egusquiza R, Wai KM, et al. Astrocytic TGF- $\beta$ signaling limits inflammation and reduces neuronal damage during central nervous system Toxoplasma infection. Journal of Immunology. 2014; 193: 139-149.

[49] Fabene PF, Navarro Mora G, Martinello M, Rossi B, Merigo F, Ottoboni L, et al. A role for leukocyte-endothelial adhesion mechanisms in epilepsy. Nature Medicine. 2008; 14: 1377-1383.

[50] Hildebrandt M, Amann K, Schröder R, Pieper T, Kolodziejczyk $\mathrm{D}$, Holthausen $\mathrm{H}$, et al. White matter angiopathy is common in pediatric patients with intractable focal epilepsies. Epilepsia. 2008; 49: 804-815.

[51] Xu D, Miller SD, Koh S. Immune mechanisms in epileptogenesis. Frontiers in Cellular Neuroscience. 2013; 7: 195.

[52] Neumann A, Abele J, Kirschstein T, Engelmann R, Sellmann T, Köhling R, et al. Mycophenolate mofetil prevents the delayed $\mathrm{T}$ cell response after pilocarpine-induced status epilepticus in mice. PLoS ONE. 2017; 12: e0187330.

[53] Pitsch J, van Loo KMJ, Gallus M, Dik A, Kamalizade D, Baumgart AK, et al. CD8(+) T-Lymphocyte-Driven Limbic Encephalitis Results in Temporal Lobe Epilepsy. Annals of Neurology. 2021; 89: 666-685.

[54] Xu D, Robinson AP, Ishii T, Duncan DS, Alden TD, Goings GE, et al. Peripherally derived T regulatory and $\gamma \delta \mathrm{T}$ cells have opposing roles in the pathogenesis of intractable pediatric epilepsy. The Journal of Experimental Medicine. 2018; 215: 1169-1186.

[55] Farina C, Aloisi F, Meinl E. Astrocytes are active players in cerebral innate immunity. Trends in Immunology. 2007; 28: 138-145.

[56] Sofroniew MV. Astrocyte Reactivity: Subtypes, States, and Functions in CNS Innate Immunity. Trends in Immunology. 2020; 41: 758-770.

[57] Biagini G, Longo D, Baldelli E, Zoli M, Rogawski MA, Bertazzoni $\mathrm{G}$, et al. Neurosteroids and epileptogenesis in the pilocarpine model: evidence for a relationship between P450scc induction and length of the latent period. Epilepsia. 2009; 50: 53-58.

[58] Baldwin KT, Eroglu C. Molecular mechanisms of astrocyteinduced synaptogenesis. Current Opinion in Neurobiology. 2017; 45: 113-120.

[59] Papa M, De Luca C, Petta F, Alberghina L, Cirillo G. Astrocyteneuron interplay in maladaptive plasticity. Neuroscience and Biobehavioral Reviews. 2014; 42: 35-54.

[60] Song H, Stevens CF, Gage FH. Astroglia induce neurogenesis from adult neural stem cells. Nature. 2002; 417: 39-44.

[61] Zamanian JL, Xu L, Foo LC, Nouri N, Zhou L, Giffard RG, et al. Genomic analysis of reactive astrogliosis. The Journal of Neuroscience. 2012; 32: 6391-6410.

[62] Anderson MA, Burda JE, Ren Y, Ao Y, O’Shea TM, Kawaguchi $\mathrm{R}$, et al. Astrocyte scar formation aids central nervous system axon 
regeneration. Nature. 2016; 532: 195-200.

[63] Liddelow SA, Guttenplan KA, Clarke LE, Bennett FC, Bohlen CJ, Schirmer L, et al. Neurotoxic reactive astrocytes are induced by activated microglia. Nature. 2017; 541: 481-487.

[64] Oztaş B, Kaya M, Küçük M, Tuğran N. Influence of hypoosmolality on the blood-brain barrier permeability during epileptic seizures. Progress in Neuro-Psychopharmacology \& Biological Psychiatry. 2003; 27: 701-704.

[65] Ilbay G, Sahin D, Ates N. Changes in blood-brain barrier permeability during hot water-induced seizures in rats. Neurological Sciences. 2003; 24: 232-235.

[66] Oby E, Janigro D. The blood-brain barrier and epilepsy. Epilepsia. 2006; 47: 1761-1774.

[67] Jabs R, Seifert G, Steinhäuser C. Astrocytic function and its alteration in the epileptic brain. Epilepsia. 2008; 49: 3-12.

[68] David Y, Cacheaux LP, Ivens S, Lapilover E, Heinemann U, Kaufer D, et al. Astrocytic Dysfunction in Epileptogenesis: Consequence of Altered Potassium and Glutamate Homeostasis? Journal of Neuroscience. 2009; 29: 10588-10599.

[69] Coulter DA, Steinhäuser C. Role of astrocytes in epilepsy. Cold Spring Harbor Perspectives in Medicine. 2015; 5: a022434.

[70] Vezzani A, Lang B, Aronica E. Immunity and Inflammation in Epilepsy. Cold Spring Harbor Perspectives in Medicine. 2015; 6: a022699.

[71] Obermeier B, Daneman R, Ransohoff RM. Development, maintenance and disruption of the blood-brain barrier. Nature Medicine. 2013; 19: 1584-1596.

[72] Vazana U, Veksler R, Pell GS, Prager O, Fassler M, Chassidim Y, et al. Glutamate-Mediated Blood-Brain Barrier Opening: Implications for Neuroprotection and Drug Delivery. Journal of Neuroscience. 2016; 36: 7727-7739.

[73] Xhima K, Weber-Adrian D, Silburt J. Glutamate Induces BloodBrain Barrier Permeability through Activation of N-Methyl-DAspartate Receptors. The Journal of Neuroscience. 2016; 36: 12296-12298.

[74] Rempe RG, Hartz AMS, Soldner ELB, Sokola BS, Alluri SR, Abner EL, et al. Matrix Metalloproteinase-Mediated Blood-Brain Barrier Dysfunction in Epilepsy. The Journal of Neuroscience. 2018; 38: 4301-4315.

[75] Vinet J, Costa A, Salinas-Navarro M, Leo G, Moons L, Arckens $\mathrm{L}$, et al. A Hydroxypyrone-Based Inhibitor of Metalloproteinase12 Displays Neuroprotective Properties in both Status Epilepticus and Optic Nerve Crush Animal Models. International Journal of Molecular Sciences. 2018; 19: 2178.

[76] Song J, Wu C, Korpos E, Zhang X, Agrawal SM, Wang Y, et al. Focal MMP-2 and MMP-9 activity at the blood-brain barrier promotes chemokine-induced leukocyte migration. Cell Reports. 2015; 10: 1040-1054.

[77] Wang Z, Zhou L, An D, Xu W, Wu C, Sha S, et al. TRPV4induced inflammatory response is involved in neuronal death in pilocarpine model of temporal lobe epilepsy in mice. Cell Death \& Disease. 2019; 10: 386.

[78] Drion CM, van Scheppingen J, Arena A, Geijtenbeek KW, Kooijman L, van Vliet EA, et al. Effects of rapamycin and curcumin on inflammation and oxidative stress in vitro and in vivo - in search of potential anti-epileptogenic strategies for temporal lobe epilepsy. Journal of Neuroinflammation. 2018; 15: 212.

[79] Kim JV, Kang SS, Dustin ML, McGavern DB. Myelomonocytic cell recruitment causes fatal CNS vascular injury during acute viral meningitis. Nature. 2009; 457: 191-195.

[80] Vezzani A, Granata T. Brain inflammation in epilepsy: experimental and clinical evidence. Epilepsia. 2005; 46: 1724-1743.

[81] Takahashi Y, Mine J, Kubota Y, Yamazaki E, Fujiwara T. A substantial number of Rasmussen syndrome patients have increased IgG, CD4+T cells, TNF $\alpha$, and Granzyme B in CSF. Epilepsia. 2009; 50: 1419-1431.

[82] Fabene PF, Laudanna C, Constantin G. Leukocyte trafficking mechanisms in epilepsy. Molecular Immunology. 2013; 55: 100104.
[83] Rossi B, Angiari S, Zenaro E, Budui SL, Constantin G. Vascular inflammation in central nervous system diseases: adhesion receptors controlling leukocyte-endothelial interactions. Journal of Leukocyte Biology. 2011; 89: 539-556.

[84] Löscher W, Friedman A. Structural, Molecular, and Functional Alterations of the Blood-Brain Barrier during Epileptogenesis and Epilepsy: A Cause, Consequence, or Both? International Journal of Molecular Sciences. 2020; 21: 591.

[85] Pekny M, Pekna M. Astrocyte reactivity and reactive astrogliosis: costs and benefits. Physiological Reviews. 2014; 94: 1077-1098.

[86] Galic MA, Riazi K, Pittman QJ. Cytokines and brain excitability. Frontiers in Neuroendocrinology. 2012; 33: 116-125.

[87] Vezzani A, Viviani B. Neuromodulatory properties of inflammatory cytokines and their impact on neuronal excitability. Neuropharmacology. 2015; 96: 70-82.

[88] Conti P, Lauritano D, Caraffa A, Gallenga CE, Kritas SK, Ronconi $\mathrm{G}$, et al. Microglia and mast cells generate proinflammatory cytokines in the brain and worsen inflammatory state: Suppressor effect of IL-37. European Journal of Pharmacology. 2020; 875: 173035.

[89] Lau LT, Yu AC. Astrocytes Produce and Release Interleukin1, Interleukin-6, Tumor Necrosis Factor Alpha and InterferonGamma Following Traumatic and Metabolic Injury. Journal of Neurotrauma. 2001; 18: 351-359.

[90] Hyvärinen T, Hagman S, Ristola M, Sukki L, Veijula K, Kreutzer $\mathrm{J}$, et al. Co-stimulation with IL- $1 \beta$ and TNF- $\alpha$ induces an inflammatory reactive astrocyte phenotype with neurosupportive characteristics in a human pluripotent stem cell model system. Scientific Reports. 2019; 9: 16944.

[91] Sofroniew MV. Multiple roles for astrocytes as effectors of cytokines and inflammatory mediators. The Neuroscientist. 2014; 20: 160-172.

[92] Liu X, Yang L, Shao L, He Y, Wu G, Bao Y, et al. Endothelial Cdk5 deficit leads to the development of spontaneous epilepsy through CXCL1/CXCR2-mediated reactive astrogliosis. Journal of Experimental Medicine. 2020; 217: e20180992.

[93] Herrmann JE, Imura T, Song B, Qi J, Ao Y, Nguyen TK, et al. STAT3 is a critical regulator of astrogliosis and scar formation after spinal cord injury. The Journal of Neuroscience. 2008; 28: 7231-7243.

[94] Okada S, Nakamura M, Katoh H, Miyao T, Shimazaki T, Ishii K, et al. Conditional ablation of Stat 3 or Socs 3 discloses a dual role for reactive astrocytes after spinal cord injury. Nature Medicine. 2006; 12: 829-834.

[95] Zhou Y, Shao A, Yao Y, Tu S, Deng Y, Zhang J. Dual roles of astrocytes in plasticity and reconstruction after traumatic brain injury. Cell Communication and Signaling. 2020; 18: 62.

[96] Sanz P, Garcia-Gimeno MA. Reactive Glia Inflammatory Signaling Pathways and Epilepsy. International journal of molecular sciences, 2020. 21: 4096.

[97] Zhang J, Sadowska GB, Chen X, Park SY, Kim J, Bodge CA, et al. Anti-IL-6 neutralizing antibody modulates blood-brain barrier function in the ovine fetus. FASEB Journal. 2015; 29: 1739-1753.

[98] Bar-Klein G, Cacheaux LP, Kamintsky L, Prager O, Weissberg I, Schoknecht K, et al. Losartan prevents acquired epilepsy via TGF$\beta$ signaling suppression. Annals of Neurology. 2014; 75: 864-875.

[99] Fernández-García S, Sancho-Balsells A, Longueville S, Hervé D, Gruart A, Delgado-García JM, et al. Astrocytic BDNF and TrkB regulate severity and neuronal activity in mouse models of temporal lobe epilepsy. Cell Death \& Disease. 2020; 11: 411.

[100] Martorell A, Wellmann M, Guiffa F, Fuenzalida M, Bonansco C. P2Y1 receptor inhibition rescues impaired synaptic plasticity and astroglial Ca-dependent activity in the epileptic hippocampus. Neurobiology of Disease. 2020; 146: 105132.

[101] Pitsch J, Kuehn JC, Gnatkovsky V, Müller JA, van Loo KMJ, de Curtis M, et al. Anti-epileptogenic and Anti-convulsive Effects of Fingolimod in Experimental Temporal Lobe Epilepsy. Molecular Neurobiology. 2019; 56: 1825-1840.

[102] Koyama R, Kinoshita S. Pro- and anti-epileptic roles of mi- 
croglia. Neural Regeneration Research. 2021; 16: 1369.

[103] Eyo UB, Peng J, Swiatkowski P, Mukherjee A, Bispo A, Wu L. Neuronal hyperactivity recruits microglial processes via neuronal NMDA receptors and microglial P2Y12 receptors after status epilepticus. The Journal of Neuroscience. 2014; 34: 1052810540.

[104] Luo C, Koyama R, Ikegaya Y. Microglia engulf viable newborn cells in the epileptic dentate gyrus. Glia. 2016; 64: 1508-1517.

[105] Fatoba O, Itokazu T, Yamashita T. Microglia as therapeutic target in central nervous system disorders. Journal of Pharmacological Sciences. 2020; 144: 102-118.

[106] Avallone R, Lucchi C, Puja G, Codeluppi A, Filaferro M, Vitale G, et al. BV-2 Microglial Cells Respond to Rotenone Toxic Insult by Modifying Pregnenolone, $5 \alpha$-Dihydroprogesterone and Pregnanolone Levels. Cells. 2020; 9: 2091.

[107] Rivest S. Regulation of innate immune responses in the brain. Nature Reviews Immunology. 2009; 9: 429-439.

[108] He J, Huang Y, Liu H, Sun X, Wu J, Zhang Z, et al. Bexarotene promotes microglia/macrophages - Specific brain - Derived Neurotrophic factor expression and axon sprouting after traumatic brain injury. Experimental Neurology. 2020; 334: 113462.

[109] Vinet J, Weering HRJV, Heinrich A, Kälin RE, Wegner A, Brouwer $\mathrm{N}$, et al. Neuroprotective function for ramified microglia in hippocampal excitotoxicity. Journal of Neuroinflammation. 2012; 9: 27.

[110] Qin L, Wu X, Block ML, Liu Y, Breese GR, Hong J, et al. Systemic LPS causes chronic neuroinflammation and progressive neurodegeneration. Glia. 2007; 55: 453-462.

[111] van Vliet EA, Forte G, Holtman L, den Burger JCG, Sinjewel A, de Vries HE, et al. Inhibition of mammalian target of rapamycin reduces epileptogenesis and blood-brain barrier leakage but not microglia activation. Epilepsia. 2012; 53: 1254-1263.

[112] Joan L, Reeves C, Michalak Z, Coppola A, Diehl B, Sisodiya SM, et al. Evidence for mTOR pathway activation in a spectrum of epilepsy-associated pathologies. Acta Neuropathologica Communications. 2014; 8: 2-71.

[113] Sosunov AA, Wu X, McGovern RA, Coughlin DG, Mikell CB, Goodman RR, et al. The mTOR pathway is activated in glial cells in mesial temporal sclerosis. Epilepsia. 2012; 53: 78-86.

[114] Fox P, Mithal DS, Somogyi JR, Vien AC, Sanchez RM, Koh S. Dexamethasone after early-life seizures attenuates increased susceptibility to seizures, seizure-induced microglia activation and neuronal injury later in life. Neuroscience Letters. 2020; 728: 134953.

[115] Koh S, Tibayan FD, Simpson JN, Jensen FE. NBQX or topiramate treatment after perinatal hypoxia-induced seizures prevents later increases in seizure-induced neuronal injury. Epilepsia. 2004; 45: 569-575.

[116] Semple BD, Dill LK, O’Brien TJ. Immune Challenges and Seizures: How Do Early Life Insults Influence Epileptogenesis? Frontiers in Pharmacology. 2020; 11: 2.

[117] Rizzi M, Perego C, Aliprandi M, Richichi C, Ravizza T, Colella $\mathrm{D}$, et al. Glia activation and cytokine increase in rat hippocampus by kainic acid-induced status epilepticus during postnatal development. Neurobiology of Disease. 2003; 14: 494-503.

[118] Vezzani A, Conti M, De Luigi A, Ravizza T, Moneta D, Marchesi $\mathrm{F}$, et al. Interleukin-1 $\beta$ Immunoreactivity and Microglia are Enhanced in the Rat Hippocampus by Focal Kainate Application: Functional Evidence for Enhancement of Electrographic Seizures. The Journal of Neuroscience. 1999; 19: 5054-5065.

[119] Chi B, Wang S, Bi S, Qin W, Wu D, Luo Z, et al. Effects of ganoderic acid a on lipopolysaccharide-induced proinflammatory cytokine release from primary mouse microglia cultures. Experimental and Therapeutic Medicine. 2018; 15: 847-853.

[120] Colonna M, Butovsky O. Microglia Function in the Central Nervous System during Health and Neurodegeneration. Annual Review of Immunology. 2019; 35: 441-468.

[121] Hanke ML, Kielian T. Toll-like receptors in health and disease in the brain: mechanisms and therapeutic potential. Clinical Science.
2011; 121: 367-387.

[122] Pelvig DP, Pakkenberg H, Stark AK, Pakkenberg B. Neocortical glial cell numbers in human brains. Neurobiology of Aging. 2008; 29: 1754-1762.

[123] Zhao H, Zhu C, Huang D. Microglial activation: an important process in the onset of epilepsy. American Journal of Translational Research. 2018; 10: 2877-2889.

[124] Choi J, Min HJ, Shin J. Increased levels of HMGB1 and proinflammatory cytokines in children with febrile seizures. Journal of Neuroinflammation. 2011; 8: 135.

[125] Schmeiser B, Li J, Brandt A, Zentner J, Doostkam S, Freiman TM. Different mossy fiber sprouting patterns in ILAE hippocampal sclerosis types. Epilepsy Research. 2017; 136: 115-122.

[126] Janz P, Savanthrapadian S, Häussler U, Kilias A, Nestel S, Kretz O, et al. Synaptic Remodeling of Entorhinal Input Contributes to an Aberrant Hippocampal Network in Temporal Lobe Epilepsy. Cerebral Cortex. 2017; 27: 2348-2364.

[127] Toscano ECDB, Vieira ÉLM, Portela ACDC, Caliari MV, Brant JAS, Giannetti AV, et al. Microgliosis is associated with visual memory decline in patients with temporal lobe epilepsy and hippocampal sclerosis: a clinicopathologic study. Epilepsy \& Behavior. 2020; 102: 106643.

[128] Andoh M, Ikegaya Y, Koyama R. Microglia modulate the structure and function of the hippocampus after early-life seizures. Journal of Pharmacological Sciences. 2020; 144: 212-217.

[129] Cunningham CL, Martínez-Cerdeño V, Noctor SC. Microglia regulate the number of neural precursor cells in the developing cerebral cortex. The Journal of Neuroscience. 2013; 33: 42164233.

[130] Sierra A, Encinas JM, Deudero JJP, Chancey JH, Enikolopov G, Overstreet-Wadiche LS, et al. Microglia shape adult hippocampal neurogenesis through apoptosis-coupled phagocytosis. Cell Stem Cell. 2010; 7: 483-495.

[131] Squarzoni P, Oller G, Hoeffel G, Pont-Lezica L, Rostaing P, Low $\mathrm{D}$, et al. Microglia modulate wiring of the embryonic forebrain. Cell Reports. 2014; 8: 1271-1279.

[132] Schafer DP, Lehrman EK, Kautzman AG, Koyama R, Mardinly AR, Yamasaki R, et al. Microglia sculpt postnatal neural circuits in an activity and complement-dependent manner. Neuron. 2012; 74: 691-705.

[133] Miyamoto A, Wake H, Ishikawa AW, Eto K, Shibata K, Murakoshi $\mathrm{H}$, et al. Microglia contact induces synapse formation in developing somatosensory cortex. Nature Communications. 2016; 7: 12540 .

[134] Augusto-Oliveira M, Arrifano GP, Lopes-Araújo A, SantosSacramento L, Takeda PY, Anthony DC, et al. What Do Microglia Really Do in Healthy Adult Brain? Cells. 2019; 8: 1293.

[135] Peri F, Nüsslein-Volhard C. Live Imaging of Neuronal Degradation by Microglia Reveals a Role for v0-ATPase a1 in Phagosomal Fusion in Vivo. Cell. 2008; 133: 916-927.

[136] Ekdahl CT, Claasen J, Bonde S, Kokaia Z, Lindvall O. Inflammation is detrimental for neurogenesis in adult brain. Proceedings of the National Academy of Sciences of the United States of America. 2003; 100: 13632-13637.

[137] Butovsky O, Ziv Y, Schwartz A, Landa G, Talpalar AE, Pluchino $\mathrm{S}$, et al. Microglia activated by IL-4 or IFN-gamma differentially induce neurogenesis and oligodendrogenesis from adult stem/progenitor cells. Molecular \& Cellular Neuroscience. 2006; 31: $149-160$.

[138] Horn KP, Busch SA, Hawthorne AL, van Rooijen N, Silver J. Another barrier to regeneration in the CNS: activated macrophages induce extensive retraction of dystrophic axons through direct physical interactions. The Journal of Neuroscience. 2008; 28: 9330-9341.

[139] Kitayama M, Ueno M, Itakura T, Yamashita T. Activated microglia inhibit axonal growth through RGMa. PLoS ONE. 2011; 6: e25234.

[140] Nikolakopoulou AM, Dutta R, Chen Z, Miller RH, Trapp BD. Activated microglia enhance neurogenesis via trypsinogen secre- 
tion. Proceedings of the National Academy of Sciences. 2013; 110: 8714-8719.

[141] Welser JV, Li L, Milner R. Microglial activation state exerts a biphasic influence on brain endothelial cell proliferation by regulating the balance of TNF and TGF- $\beta 1$. Journal of Neuroinflammation. 2010; 7: 89.

[142] Paolicelli RC, Bolasco G, Pagani F, Maggi L, Scianni M, Panzanelli $\mathrm{P}$, et al. Synaptic pruning by microglia is necessary for normal brain development. Science. 2011; 333: 1456-1458.

[143] Wake H, Moorhouse AJ, Jinno S, Kohsaka S, Nabekura J. Resting microglia directly monitor the functional state of synapses in vivo and determine the fate of ischemic terminals. The Journal of Neuroscience. 2009; 29: 3974-3980.

[144] Hu X, Leak RK, Shi Y, Suenaga J, Gao Y, Zheng P, et al. Microglial and macrophage polarization - new prospects for brain repair. $\mathrm{Na}-$ ture Reviews Neurology. 2015; 11: 56-64.

[145] Shi H, Wang X, Quan H, Yan L, Pei X, Wang R, et al. Effects of Betaine on LPS-Stimulated Activation of Microglial M1/M2 Phenotypes by Suppressing TLR4/NF- $x B$ Pathways in N9 Cells. Molecules. 2019; 24: 367.

[146] Liu L, Xu Y, Dai H, Tan S, Mao X, Chen Z. Dynorphin activation of kappa opioid receptor promotes microglial polarization toward M2 phenotype via TLR4/NF- $x$ B pathway. Cell \& Bioscience. 2020; 10: 42.

[147] Sen T, Saha P, Gupta R, Foley LM, Jiang T, Abakumova OS, et al. Aberrant ER Stress Induced Neuronal-IFN $\beta$ Elicits White Matter Injury Due to Microglial Activation and T-Cell Infiltration after TBI. The Journal of Neuroscience. 2020; 40: 424-446.

[148] Peng J, Wang K, Xiang W, Li Y, Hao Y, Guan Y. Rosiglitazone polarizes microglia and protects against pilocarpine-induced status epilepticus. CNS Neuroscience \& Therapeutics. 2019; 25: $1363-$ 1372.

[149] Fan H, Tang H, Chen Z, Wang H, Zhang L, Jiang $\mathrm{Y}$, et al. Inhibiting HMGB1-RAGE axis prevents pro-inflammatory macrophages/microglia polarization and affords neuroprotection after spinal cord injury. Journal of Neuroinflammation. 2020; 17: 295.

[150] Bohlen CJ, Priel A, Zhou S, King D, Siemens J, Julius D. A bivalent tarantula toxin activates the capsaicin receptor, TRPV1, by targeting the outer pore domain. Cell. 2010; 141: 834-845.

[151] Kichko TI, Neuhuber W, Kobal G, Reeh PW. The roles of TRPV1, TRPA1 and TRPM8 channels in chemical and thermal sensitivity of the mouse oral mucosa. The European Journal of Neuroscience. 2018; 47: 201-210.

[152] Saffarzadeh F, Eslamizade MJ, Ghadiri T, Modarres Mousavi SM, Hadjighassem M, Gorji A. Effects of TRPV1 on the hippocampal synaptic plasticity in the epileptic rat brain. Synapse. 2015; 69: 375-383.

[153] Saffarzadeh F, Eslamizade MJ, Mousavi SMM, Abraki SB, Hadjighassem MR, Gorji A. TRPV1 receptors augment basal synaptic transmission in CA1 and CA3 pyramidal neurons in epilepsy. Neuroscience. 2016; 314: 170-178.

[154] Kong W, Wang X, Yang X, Huang W, Han S, Yin J, et al. Activation of TRPV1 Contributes to Recurrent Febrile Seizures Inhibiting the Microglial M2 Phenotype in the Immature Brain. Frontiers in Cellular Neuroscience. 2019; 13: 442.

[155] Wen X, Han XR, Wang YJ, Wang S, Shen M, Zhang ZF, et al. MicroRNA-421 suppresses the apoptosis and autophagy of hippocampal neurons in epilepsy mice model by inhibition of the TLR/MYD88 pathway. Journal of Cellular Physiology. 2018; 233: 7022-7034.

[156] Wang N, Han X, Liu H, Zhao T, Li J, Feng Y, et al. Myeloid differentiation factor 88 is up-regulated in epileptic brain and contributes to experimental seizures in rats. Experimental Neurology. 2017; 295: 23-35.

[157] Liu J, Wu S, Zhang H, Kuang F. Inhibition of MyD88 Signaling Skews Microglia/Macrophage Polarization and Attenuates Neuronal Apoptosis in the Hippocampus after Status Epilepticus in Mice. Neurotherapeutics. 2018; 15: 1093-1111.
[158] Fanous MYZ, Phillips AJ, Windsor JA. Mesenteric lymph: the bridge to future management of critical illness. Journal of the Pancreas. 2007; 8: 374-399.

[159] Erny D, Hrabě de Angelis AL, Jaitin D, Wieghofer P, Staszewski $\mathrm{O}$, David $\mathrm{E}$, et al. Host microbiota constantly control maturation and function of microglia in the CNS. Nature Neuroscience. 2015; 18: 965-977.

[160] Shreiner AB, Kao JY, Young VB. The gut microbiome in health and in disease. Current Opinion in Gastroenterology. 2015; 31: 69-75.

[161] Macfabe DF. Short-chain fatty acid fermentation products of the gut microbiome: implications in autism spectrum disorders. Microbial Ecology in Health and Disease. 2012; 23: 19260.

[162] Braniste V, Al-Asmakh M, Kowal C, Anuar F, Abbaspour A, Tóth $\mathrm{M}$, et al. The gut microbiota influences blood-brain barrier permeability in mice. Science Translational Medicine. 2014; 6: 263 ra158.

[163] Welcome MO. Gut Microbiota Disorder, Gut Epithelial and Blood-Brain Barrier Dysfunctions in Etiopathogenesis of Dementia: Molecular Mechanisms and Signaling Pathways. NeuroMolecular Medicine. 2019; 21: 205-226.

[164] Li H, Sun J, Wang F, Ding G, Chen W, Fang R, et al. Sodium butyrate exerts neuroprotective effects by restoring the blood-brain barrier in traumatic brain injury mice. Brain Research. 2016; 1642: 70-78.

[165] Li H, Sun J, Du J, Wang F, Fang R, Yu C, et al. Clostridium butyricum exerts a neuroprotective effect in a mouse model of traumatic brain injury via the gut-brain axis. Neurogastroenterology and Motility. 2017; 30: e13260.

[166] Kim HJ, Rowe M, Ren M, Hong J, Chen P, Chuang D. Histone deacetylase inhibitors exhibit anti-inflammatory and neuroprotective effects in a rat permanent ischemic model of stroke: multiple mechanisms of action. The Journal of Pharmacology and Experimental Therapeutics. 2007; 321: 892-901.

[167] Leclercq S, Mian FM, Stanisz AM, Bindels LB, Cambier E, BenAmram $\mathrm{H}$, et al. Low-dose penicillin in early life induces long-term changes in murine gut microbiota, brain cytokines and behavior. Nature Communications. 2017; 8: 15062.

[168] Medel-Matus J, Shin D, Dorfman E, Sankar R, Mazarati A. Facilitation of kindling epileptogenesis by chronic stress may be mediated by intestinal microbiome. Epilepsia Open. 2018; 3: 290-294.

[169] Arulsamy A, Tan QY, Balasubramaniam V, O'Brien TJ, Shaikh MF. Gut Microbiota and Epilepsy: a Systematic Review on their Relationship and Possible Therapeutics. ACS Chemical Neuroscience. 2020; 11: 3488-3498.

[170] Şafak B, Altunan B, Topçu B, Eren Topkaya A. The gut microbiome in epilepsy. Microbial Pathogenesis. 2020; 139: 103853.

[171] Fan Y, Wang H, Liu X, Zhang J, Liu G. Crosstalk between the Ketogenic Diet and Epilepsy: from the Perspective of Gut Microbiota. Mediators of Inflammation. 2019; 2019: 1-9.

[172] Holmes M, Flaminio Z, Vardhan M, Xu F, Li X, Devinsky O, et al. Cross talk between drug-resistant epilepsy and the gut microbiome. Epilepsia. 2020; 61: 2619-2628.

[173] Olson CA, Vuong HE, Yano JM, Liang QY, Nusbaum DJ, Hsiao EY. The Gut Microbiota Mediates the Anti-Seizure Effects of the Ketogenic Diet. Cell. 2018; 174: 497.

[174] Giordano C, Marchiò M, Timofeeva E, Biagini G. Neuroactive peptides as putative mediators of antiepileptic ketogenic diets. Frontiers in Neurology. 2014; 5: 63.

[175] Vuong HE, Yano JM, Fung TC, Hsiao EY. The Microbiome and Host Behavior. Annual Review of Neuroscience. 2017; 40: 21-49.

[176] Sommer F, Bäckhed F. The gut microbiota-masters of host development and physiology. Nature Reviews. Microbiology. 2013; 11: $227-238$.

[177] Zmora N, Suez J, Elinav E. You are what you eat: diet, health and the gut microbiota. Nature Reviews. Gastroenterology \& Hepatology. 2019; 16: 35-56.

[178] Saghazadeh A, Rezaei N. Immuno-epileptology. Expert Review of Clinical Immunology. 2017; 13: 845-847. 
[179] Quek AML, Britton JW, McKeon A, So E, Lennon VA, Shin C, et al. Autoimmune epilepsy: clinical characteristics and response to immunotherapy. Archives of Neurology. 2012; 69: 582-593.

[180] Irani SR, Buckley C, Vincent A, Cockerell OC, Rudge P, Johnson $\mathrm{MR}$, et al. Immunotherapy-responsive seizure-like episodes with potassium channel antibodies. Neurology. 2008; 71: 1647-1648.

[181] Peltola J, Kulmala P, Isojärvi J, Saiz A, Latvala K, Palmio J, et al. Autoantibodies to glutamic acid decarboxylase in patients with therapy-resistant epilepsy. Neurology. 2000; 55: 46-50.

[182] McKnight K, Jiang Y, Hart Y, Cavey A, Wroe S, Blank M, et al. Serum antibodies in epilepsy and seizure-associated disorders. Neurology. 2005; 65: 1730-1736.

[183] Mao L, Ding J, Peng W, Ma Y, Zhang Y, Fan W, et al. Interictal interleukin-17a levels are elevated and correlate with seizure severity of epilepsy patients. Epilepsia. 2013; 54: e142-e145.

[184] Chow J, Mazmanian SK. Getting the Bugs out of the Immune System: do Bacterial Microbiota "Fix" Intestinal T Cell Responses? Cell Host \& Microbe. 2009; 5: 8-12.

[185] Owens GC, Garcia AJ, Mochizuki AY, Chang JW, Reyes SD, Salamon $\mathrm{N}$, et al. Evidence for Innate and Adaptive Immune Responses in a Cohort of Intractable Pediatric Epilepsy Surgery Patients. Frontiers in Immunology. 2019. 10: 121.

[186] Owens GC, Erickson KL, Malone CC, Pan C, Huynh MN, Chang $\mathrm{JW}$, et al. Evidence for the involvement of gamma delta $\mathrm{T}$ cells in the immune response in Rasmussen encephalitis. Journal of Neuroinflammation. 2015; 12: 134.

[187] Mucida D, Park Y, Kim G, Turovskaya O, Scott I, Kronenberg M, et al. Reciprocal TH17 and regulatory T cell differentiation mediated by retinoic acid. Science. 2007; 317: 256-260.

[188] Ait-Belgnaoui A, Colom A, Braniste V, Ramalho L, Marrot A, Cartier C, et al. Probiotic gut effect prevents the chronic psychological stress-induced brain activity abnormality in mice. Neurogastroenterology and Motility. 2014; 26: 510-520.

[189] Möhle L, Mattei D, Heimesaat MM, Bereswill S, Fischer A, Alutis M, et al. Ly6C(hi) Monocytes Provide a Link between AntibioticInduced Changes in Gut Microbiota and Adult Hippocampal Neurogenesis. Cell Reports. 2016; 15: 1945-1956.

[190] Heiss CN, Olofsson LE. The role of the gut microbiota in development, function and disorders of the central nervous system and the enteric nervous system. Journal of Neuroendocrinology. 2019; 31: e12684.

[191] Ma Q, Xing C, Long W, Wang HY, Liu Q, Wang R. Impact of microbiota on central nervous system and neurological diseases: the gut-brain axis. Journal of Neuroinflammation. 2019; 16: 53.

[192] Wikoff WR, Anfora AT, Liu J, Schultz PG, Lesley SA, Peters $\mathrm{EC}$, et al. Metabolomics analysis reveals large effects of gut mi- croflora on mammalian blood metabolites. Proceedings of the $\mathrm{Na}$ tional Academy of Sciences. 2009; 106: 3698-3703.

[193] Zhang J, Yu C, Zhang X, Chen H, Dong J, Lu W, et al. Porphyromonas gingivalis lipopolysaccharide induces cognitive dysfunction, mediated by neuronal inflammation via activation of the TLR4 signaling pathway in C57BL/6 mice. Journal of Neuroinflammation. 2018; 15: 37.

[194] Xie G, Zhou Q, Qiu C, Dai W, Wang H, Li Y, et al. Ketogenic diet poses a significant effect on imbalanced gut microbiota in infants with refractory epilepsy. World Journal of Gastroenterology. 2017; 23: 6164-6171.

[195] Bagheri S, Heydari A, Alinaghipour A, Salami M. Effect of probiotic supplementation on seizure activity and cognitive performance in PTZ-induced chemical kindling. Epilepsy \& Behavior. 2019; 95: 43-50.

[196] van de Wouw M, Schellekens H, Dinan TG, Cryan JF. Microbiota-Gut-Brain Axis: Modulator of Host Metabolism and Appetite. The Journal of Nutrition. 2017; 147: 727-745.

[197] Cammarota G, Ianiro G, Bibbò S, Gasbarrini A. Gut microbiota modulation: probiotics, antibiotics or fecal microbiota transplantation? Internal and Emergency Medicine. 2014; 9: 365-373.

[198] Zavala-Tecuapetla C, Cuellar-Herrera M, Luna-Munguia H. Insights into Potential Targets for Therapeutic Intervention in Epilepsy. International Journal of Molecular Sciences. 2020; 21: 8573.

[199] Liu F, Cheng X, Zhong S, Liu C, Jolkkonen J, Zhang X, et al. Communications Between Peripheral and the Brain-Resident Immune System in Neuronal Regeneration After Stroke. Frontiers in Immunology. 2020; 11: 1931.

[200] Liu Z, Cheng X, Zhong S, Zhang X, Liu C, Liu F, et al. Peripheral and Central Nervous System Immune Response Crosstalk in Amyotrophic Lateral Sclerosis. Frontiers in Neuroscience. 2020; 14: 575.

[201] Salari V, Mengoni F, Del Gallo F, Bertini G, Fabene PF. The Anti-Inflammatory Properties of Mesenchymal Stem Cells in Epilepsy: Possible Treatments and Future Perspectives. International Journal of Molecular Sciences. 2020; 21: 9683.

[202] Rawat K, Singh N, Kumari P, Saha L. A review on preventive role of ketogenic diet (KD) in CNS disorders from the gut microbiota perspective. Reviews in the Neurosciences. 2021; 32: 143-157.

[203] Iannone LF, Gómez-Eguílaz M, Citaro R, Russo E. The potential role of interventions impacting on gut-microbiota in epilepsy. Expert Review of Clinical Pharmacology. 2020; 13: 423-435.

[204] Mejía-Granados DM, Villasana-Salazar B, Lozano-García L, Cavalheiro EA, Striano P. Gut-microbiota-directed strategies to treat epilepsy: clinical and experimental evidence. Seizure. 2021; 90: 80-92. 